\title{
Physico-chemical, antioxidant and sensorial properties of fruit leathers made from "Malga" and "Murano" strawberry cultivars
}

\section{Violeta Nour}

\author{
University of Craiova, Craiova, Romania
}

Keywords:

Strawberry

Fruit leathers

Dehydration

Anthocyanins

Phenolics

Antioxidant

Article history:

Received

11.04.2021

Received in revised

form 20.08.2021

Accepted

30.12.2021

Corresponding

author:

Violeta Nour

E-mail:

vionor@yahoo.com

DOI:

$10.24263 / 2304-$

974X-2021-10-4-8

\section{Abstract}

Introduction. Strawberries are recognized as an antioxidant source due to their high content of anthocyanins, other phenolic compounds and ascorbic acid. The objective of this study was to formulate and to characterize fruit leather made from two strawberry cultivars using honey and lemon juice as ingredients.

Materials and methods. The fresh fruits were pureed, mixed with honey and lemon juice and then dried in a dehydrator at $57{ }^{\circ} \mathrm{C}$ for 6 hours. Both fruit homogenates and leathers were characterized in terms of moisture content, total soluble solids content, titratable acidity, color by CIE $L^{*} a^{*} b^{*}$ system, total phenolic content by FolinCiocalteu method, total flavonoid content by the aluminium nitrate method, total anthocyanin content by the $\mathrm{pH}$ differential spectrophotometric method and antioxidant activity by the DPPH (2diphenyl-1-picrylhydrazyl) procedure. A 9-point hedonic scale was used to evaluate strawberry leathers for color, sweetness, sourness, flavor, texture, and general acceptability.

Results and discussion. There was a substantial increase in soluble solids content and titratable acidity of both strawberry leathers as a result of honey and lemon juice addition and drying. Fresh strawberry homogenates were lighter (higher $\mathrm{L}^{*}$ values) as compared to fruit leathers. In addition, the color parameter $a^{*}$ showed a significant decrease in both cultivars after drying, that may be attributed to the oxidation of anthocyanins as well as thermal degradation. The total phenolic, flavonoid and anthocyanin content were higher both in the fresh homogenate and in the leather of "Malga" cultivar than in "Murano". However, DPPH antioxidant activity was slightly higher in "Murano" (35.21 mmol Trolox/100 g) than in "Malga" homogenates (34.45 mmol Trolox/100 g) but differences were not significant. After dehydration, the anthocyanin content in the strawberry leather decreased by $67.38 \%$ ("Murano") and $64.07 \%$ ("Malga"), while the total phenolic content decreased by 43.81\% ("Murano") and 32.33\% ("Malga"). In addition, after drying, reductions in the DPPH antioxidant activity of $40.5 \%$ ("Murano") and $38.5 \%$ ("Malga") were observed. In terms of sensory evaluation, "Murano" leather stand out as compared with "Malga", due to its more reddish color, stronger sweetness, lower sourness and more pleasant texture.

Conclusions. Apart from their attractive appearance, taste and flavor, strawberry leathers are a good source of natural antioxidants including anthocyanins and other phenolic compounds. 


\section{Introduction}

Based on its unique taste and flavor as well as low caloric value, strawberry (Fragaria $x$ ananassa, Duch.) is among the most desirable fruit worldwide. Strawberries are a rich source of several nutritional and bioactive compounds such as easily digestible sugars, organic acids, minerals, vitamins and phenolic compounds (Forbes-Hernandez et al., 2016; Kowalska et al., 2018), which take part in various health-promoting and disease preventive effects (Afrin et al., 2016). The main phenolic compounds in strawberry are anthocyanins, flavonols, and hydroxycinnamic and ellagic acid derivatives, which exert antioxidant, antiinflammatory, anticarcinogenic, antimutagenic, antibacterial or antiviral activity (Aaby et al., 2007; Ariza et al., 2018).

Due to moisture loss, mechanical injury, and physical and microbial decay (Velde et al., 2013) fresh strawberries have a short postharvest life (5 to 7 days) when stored at $0-4^{\circ} \mathrm{C}$ while fruit losses can range up to $40 \%$ during storage (Guo et al. 2018). As a consequence, there is a current interest in the enhancement of strawberry fruit shelf life by using various preservation techniques including ultraviolet light, controlled atmosphere storage, modified atmosphere packaging, high oxygen treatment, UV-C or gamma irradiation, edible coatings, and chemical treatments (Parvez and Wani, 2018; Nour et al., 2021).

In order to reduce the postharvest losses and to respond to consumer demand for new value-added products, strawberries are subjected to processed, mainly into jams or beverages (Kowalska et al., 2018). Recently, strawberry leathers have been considered as an alternative dessert or replacement for confectionery due to their high nutritional values and sensorial properties (Phuong et al., 2016).

An alternative for preserving and adding value to various fruits using dehydration is the development of fruit leathers (Diamante et al., 2014). They are dried sheets or flexible strips of fruit pulp that taste sweet and have a soft, rubbery texture (Addai et al., 2016). Fruits leathers are made typically by hot air drying of fruit puree or fruit juice concentrate, with or without the addition of sweeteners (glucose syrup, honey or sugar such as sucrose, glucose, and fructose), thickeners (starch, pectin, gelatin, alginate, gums, and cellulose derivatives) or preservatives (sulfur dioxide and sorbic acid) (Da Silva Simão et al., 2020). Artificial and natural colors, flavors, and citric acid can also be added (Al-Hinai et al., 2013). Fruit leathers could serve as a nutritious breakfast, snack or dessert as they are rich in dietary fiber, carbohydrate, vitamins, minerals and antioxidants (Momchilova et al., 2016; Setiaboma et al., 2019).

Thus, the production of fruit leather mainly involves the steps of processing the fruit into the puree or concentrate juice, the addition of ingredients, and drying. Fruit leathers are dried at 30 to $80{ }^{\circ} \mathrm{C}$ until the final moisture content of $12-20 \%$ has been reached (Diamante et al., 2014; Phuong et al., 2016). However, many changes in the color, texture, flavor, odor and physio-chemical properties of the product as well as loss of desirable nutrients take place during drying (Bandaru and Bakshi, 2020; Suna, 2019). The leathers tend to darker and turn to brown due to the sensitivity of the pigments to the drying temperature, and to the enzymatic oxidation of polyphenols (Momchilova et al., 2016).

"Malga" and "Murano" are two new strawberry cultivars with high sensorial and nutritional properties. "Malga" is a cultivar of Russian origin, bred in Italy, having large fruits with an attractive orange tint. The pulp is moderately dense and juicy, with pronounced sweetness, delicate sourness and persistent aroma (https://gardenluxen.designluxpro.com/sad-i-ogorod/yagody/opisanie-i-harakteristiki-remontantnoy-klubnikimalga-malga.html). "Murano" is an Italian cultivar with excellent product characteristics. The berries are red-orange in color, very sweet, aromatic, having an excellent balance of 
sugar and acid (https://naturelux.woman365pro.com/en/klubnika-zemlyanika/sort-klubnikimurano.html).

The aim of this study was to investigate the effects of the cultivar and of the drying process on antioxidant content, physico-chemical and sensorial properties of strawberry fruit leathers made with honey and lemon juice as natural ingredients.

\section{Materials and methods}

\section{Samples collection and preparation}

Strawberries (Fragaria x ananassa cvs. "Malga" and "Murano") used in the present study were hand-harvested at the commercially mature stage of ripening from a farm in Marsani, Dolj county $\left(44^{\circ} 00^{\prime} \mathrm{N} 23^{\circ} 59^{\prime} \mathrm{E}\right)$. The fruits were sorted to eliminate damaged, poor quality, and unripe fruits, and selected for uniform size, color and maturity. After removing the calyx and peduncle, fruits were washed in tap water, drained at ambient temperature, and then stored at $4{ }^{\circ} \mathrm{C}$ until fruit leather processing and analysis.

\section{Chemicals}

Folin-Ciocalteu reagent, gallic acid, 2,2-diphenyl-1-picrylhydrazyl (DPPH), 6hydroxy-2,5,7,8-tetramethylchroman-2-carboxylic acid (Trolox) and sodium acetate were purchased from Sigma-Aldrich (Germany). Sodium carbonate and aluminium nitrate were purchased from Merck (Darmstadt, Germany). All other chemicals used were of analytical grade.

\section{Preparation of fruit leather}

Five hundred grams of strawberries were ground using a home type blender (Bosch MS61B6170, $1000 \mathrm{~W}$, Germany) until obtaining a purée (2 minutes). Honey (4\%, w/w) and lemon juice $(2 \%, w / w)$ were weighed and mixed with strawberry purees. The blending process was carried out at high speed for 2 min to get a smooth mixture. The mixture was then spread evenly as a thin layer over carbon steel trays covered with parchment paper smeared with oil to prevent the strawberry leather from sticking to paper after drying. The trays were placed in a cabinet type laboratory dryer (Deca + SS Design, Profimatic, Romania) set at $57{ }^{\circ} \mathrm{C}$. The fruit puree mixtures were dried from one side (top surface) with air flowing parallel to the leathers. Moisture loss of the samples was determined periodically during drying by removing the sample from the oven and weighing the tray using a $0.01 \mathrm{~g}$ sensitive digital scale (Radvag WLC/6/A2, Poland). Drying was terminated when the calculated moisture content of the dried sample reached $10-12 \%$. After drying, fruit leather samples were pulled from the surface, packaged with a low density polyethylene film and stored at room temperature until analyzed. The drying experiments were carried out in triplicate.

\section{Physicochemical properties of strawberry fruits and leathers}

The moisture content of the initial fruit homogenates was determined by drying the samples in a forced air oven (Memmert, Germany) at $105{ }^{\circ} \mathrm{C}$ until constant weight was obtained. Triplicate samples were used for the determination of moisture content and the average values were reported. 
Homogenous fruit samples were prepared by blending twenty fruits from replicate sample in an electrical blender. The total soluble solids content was measured with a digital refractometer (Hanna Instruments, Woonsocket, USA), and the results were expressed as percentage of soluble solids. Titratable acidity was determined titrimetrically in $10 \mathrm{~g}$ of homogenate or fruit leather, made up to $100 \mathrm{~g}$ with deionized water and titrated to $\mathrm{pH} 8.2$ with $0.1 \mathrm{~N} \mathrm{NaOH}$ solution. The results were expressed as grams of citric acid per $100 \mathrm{~g}$ fresh weight. Two independent extracts were prepared for each sample and each one was titrated in duplicate.

\section{Color measurement}

The color values (CIE $L^{*}, a^{*}$ and $b^{*}$ ) of the fruit purées and leathers were measured with a PCE-CSM1 reflectance colorimeter (PCE Instruments, UK) calibrated against a white standard, where $L^{*}$ is a measure for lightness, $a^{*}$ for redness and $b^{*}$ for yellowness. Chroma (C) was calculated as $\left(a^{* 2}+b^{* 2}\right)^{1 / 2}$ while hue angle (h) was calculated as $\arctan \left(-b^{*} / a^{*}\right)$. The analysis was performed on three samples from each cultivar with five readings for each sample.

Color degradation after drying was evaluated by determining the browning degree and expressed as the color difference $(\Delta \mathrm{E})$, as follows:

$$
\Delta \mathrm{E}=\sqrt{(\mathrm{L} 1-\mathrm{L} 0)^{2}+(\mathrm{a} 1-\mathrm{a} 0)^{2}+(\mathrm{b} 1-\mathrm{b} 0)^{2}},
$$

where L1, a1, b1 represent color values of leather after the drying process, while L0, $\mathrm{a} 0, \mathrm{~b} 0$ are color values of fresh homogenate.

\section{Extraction of phenolic compounds}

Fruit and leather samples $(1.5 \mathrm{~g})$ were extracted with $10 \mathrm{~mL}$ methanol in a Bandelin Sonorex Digital 10P ultrasonic bath (Bandelin Electronic GmbH, Germany) for $60 \mathrm{~min}$ at ambient temperature. After extraction, the samples were centrifuged for $5 \mathrm{~min}$ at $4200 \mathrm{rpm}$. Supernatants were collected, filtered through $0.45 \mu \mathrm{m}$ polyamide membranes and used for the assays.

\section{Total phenolic content}

Total phenolic content was assessed by using the Folin-Ciocalteu spectrophotometric method as described by Singleton and Rossi (1965) with slight modifications. Briefly, aliquots of extracts $(0.1 \mathrm{~mL})$ were mixed with $5 \mathrm{~mL}$ of distilled water and $0.5 \mathrm{~mL}$ of FolinCiocalteu reagent in a test tube. After $2 \mathrm{~min}, 4 \mathrm{~mL}$ of $7.5 \%$ sodium carbonate aqueous solution were added and the mixture was allowed to stand for $30 \mathrm{~min}$ at $40{ }^{\circ} \mathrm{C}$ in a dark. The absorbance of each sample was read at $765 \mathrm{~nm}$ using a Varian Cary $50 \mathrm{UV}$ spectrophotometer (Varian Co., USA). Results were expressed as mg gallic acid equivalent per 100 fresh weight (fw).

\section{Total flavonoid content}

The total flavonoid content was determined according to the aluminium nitrate spectrophotometric method described by Mohammadzadeh et al. (2007). $0.5 \mathrm{~mL}$ fruit or leather extract prepared as described above was mixed with $0.1 \mathrm{~mL}$ aluminum nitrate $(10 \%)$, 
$0.1 \mathrm{~mL}$ sodium acetate $(1 \mathrm{M})$ and $4.3 \mathrm{~mL}$ methanol. After incubation for $40 \mathrm{~min}$ at room temperature, the absorbance of the mixture was read at $415 \mathrm{~nm}$ on a Varian Cary 50 UV-VIS spectrophotometer (Varian Co., USA). A calibration curve was prepared using a standard solution of quercetin. Results were expressed as $\mathrm{mg}$ of quercetin equivalents (QE) per 100 fresh weight (fw).

\section{Total anthocyanin content}

Anthocyanins were extracted from fruit homogenate or fruit leather with methanol acidified with $0.1 \% \mathrm{HCl}(\mathrm{v} / \mathrm{v})$. The quantification of total anthocyanins was performed using the $\mathrm{pH}$ differential spectrophotometric method described by Giusti and Wrolstad (2001).

Each extract $(2 \mathrm{~mL})$ was separately diluted to $25 \mathrm{~mL}$ with $0.025 \mathrm{M}$ potassium chloride buffer $(\mathrm{pH} 1.0)$ and $0.4 \mathrm{M}$ sodium acetate buffer $(\mathrm{pH} 4.5)$. The diluted solutions were then left at room temperature for $15 \mathrm{~min}$ and the absorbance of each dilution was read at 510 and 700 $\mathrm{nm}$. The total anthocyanin content was calculated using the following equation:

Total anthocyanins $(\mathrm{mg} \mathrm{CGE} / \mathrm{L})=(\mathrm{A} \times \mathrm{MW} \times \mathrm{DF} \times 1,000) / \varepsilon$

where $\mathrm{A}=(\mathrm{A} 510 \mathrm{~nm}-\mathrm{A} 700 \mathrm{~nm}) \mathrm{pH} 1.0-(\mathrm{A} 510 \mathrm{~nm}-\mathrm{A} 700 \mathrm{~nm}) \mathrm{pH} 4.5 ; \mathrm{MW}$ (molecular weight $)=449.2 \mathrm{~g} / \mathrm{mol}$ for cyanidin-3-O-glucoside; $\mathrm{DF}=$ dilution factor of the samples; $\varepsilon$ (molar absorbtivity of cyanidin-3-glucoside) $=29,600 \mathrm{~L} /(\mathrm{mol} \cdot \mathrm{cm})$. Results were expressed as milligrams of cyanidin 3-O-glucoside equivalents (CGE) per $100 \mathrm{~g}$ of fresh weight (fw).

\section{DPPH radical scavenging activity}

Antioxidant activity of the fruit and leather samples was measured using a DPPH (2diphenyl-1-picrylhydrazyl) procedure described by Hatano et al. (1988). Briefly, aliquots of extracts $(50 \mu \mathrm{L})$ were mixed with $3 \mathrm{~mL}$ of a $0.004 \%(\mathrm{v} / \mathrm{v})$ DPPH methanolic solution. After $30 \mathrm{~min}$, the absorbance was read at $517 \mathrm{~nm}$ using a Varian Cary $50 \mathrm{UV}$ spectrophotometer (Varian Co., USA). The inhibition of the DPPH radical by the samples was calculated according to the following formula: DPPH scavenging activity $(\%)=\left[\begin{array}{ll}1 & -\end{array}\right.$ Abs.sample/Abs.blank] $\times 100$. The DPPH scavenging activity was subsequently calculated with respect to the 6-hydroxy-2,5,7,8-tetramethylchroman-2-carboxylic acid (Trolox), which was used as a standard reference. Results were expressed as milimoles Trolox equivalents per $100 \mathrm{~g}$ of fresh weight.

\section{Sensorial analysis}

A 9-point hedonic scale varying from like extremely (9) to dislike extremely (1) was used to evaluate strawberry leather samples for color, sweetness, sourness, flavor, texture, and general acceptability. The sensory panel included ten panelists consisting of graduate students and staff members from the Department of Food Science, University of Craiova.

\section{Statistical analysis}

All experiments were done in three replicates and results reported by mean \pm standard deviation. The means were compared by using the Least Significant Difference (LSD) test and statistical significance was considered at $\mathrm{p}<0.05$. Statgraphics Centurion XVI software (StatPoint Technologies, VA, USA) was employed in this study. 


\section{Results}

The moisture content, titratable acidity and soluble solids content of fresh fruits and leathers for the two strawberry cultivars are shown in Table 1. The cultivars exhibited considerable differences in terms of titratable acidity and soluble solids content $(\mathrm{p}<0.05)$. The "Malga" cultivar had a higher level of titratable acidity while "Murano" cultivar had a higher soluble solids content. The results indicated that the titratable acidity of fresh strawberries was between $0.51 \%$ ("Murano") and $0.83 \%$ ("Malga") of citric acid equivalent. After processing, the highest acidity was found in the "Malga" leather (3.48\%) as compared with "Murano" leather $(2.02 \%)$ (Table 1$)$.

Effect of processing on moisture content, titratable acidity and soluble solids

Table 1 of two strawberry cultivars

\begin{tabular}{|l|c|c|c|c|c|c|}
\hline Cultivars & \multicolumn{2}{|c|}{$\begin{array}{c}\text { Moisture content } \\
\text { (\%) }\end{array}$} & \multicolumn{2}{c|}{$\begin{array}{c}\text { Titratable acidity } \\
\text { (g citric acid/100 g) }\end{array}$} & \multicolumn{2}{c|}{$\begin{array}{c}\text { Soluble solids } \\
\text { (\%) }\end{array}$} \\
\cline { 2 - 7 } & Fresh & Leather & Fresh & Leather & Fresh & Leather \\
\hline "Murano" & $88.22 \pm 0.53$ & $12.61 \pm 0.47^{\mathrm{a}}$ & $0.51 \pm 0.03^{\mathrm{b}}$ & $2.02 \pm 0.09^{\mathrm{b}}$ & $10.43 \pm 0.68^{\mathrm{a}}$ & $43.26 \pm 0.88^{\mathrm{a}}$ \\
\hline "Malga" & $89.12 \pm 1.08$ & $9.85 \pm 0.15^{\mathrm{b}}$ & $0.83 \pm 0.04^{\mathrm{a}}$ & $3.48 \pm 0.12^{\mathrm{a}}$ & $9.65 \pm 0.46^{\mathrm{b}}$ & $39.50 \pm 0.69^{\mathrm{b}}$ \\
\hline
\end{tabular}

* Results show means \pm standard deviation. Different superscript letters indicate a significant difference at $\mathrm{p}<0.05$ level between cultivars

The fruits of the two strawberry cultivars also differed greatly with regard to soluble solids content $(\mathrm{p}<0.05)$. "Murano" fruits displayed the highest levels of soluble solids content $(10.43 \%)$ as compared to "Malga" $(9.65 \%)$. There was a substantial increase in the soluble solids content of both fruit leathers because of honey addition and drying, with levels of 43.26\% and 39.5\% respectively for "Murano" and "Malga" leathers. Previous studies reported higher levels of soluble solids content in fruit leathers (Addai et al., 2016; Kumar et al., 2010; Phimpharian et al., 2011).

Vaidya et al. (2007) reported a soluble solids content of $68^{\circ}$ Brix in kiwifruit leather made with $15 \%$ sugar addition and dried for 15 hours at $45^{\circ} \pm 2^{\circ} \mathrm{C}$. The low level of honey addition in this experiment (4\%) may be one of the reasons for the lower soluble solids content in our strawberry leathers.

Table 2

Effect of processing on color values of two strawberry cultivars

\begin{tabular}{|l|c|c|c|c|}
\hline \multirow{2}{*}{ Cultivars } & \multicolumn{2}{|c|}{ Fresh } & \multicolumn{2}{c|}{ Leather } \\
\cline { 2 - 5 } & "Murano" & "Malga" & "Murano" & "Malga" \\
\hline$L^{*}$ & $34.04 \pm 2.95$ & $32.75 \pm 3.44$ & $31.43 \pm 1.12$ & $30.20 \pm 1.50$ \\
\hline$a^{*}$ & $33.35 \pm 3.72$ & $27.95 \pm 7.76$ & $29.03 \pm 5.18$ & $24.22 \pm 1.49$ \\
\hline$b^{*}$ & $21.16 \pm 2.68^{\mathrm{b}}$ & $29.98 \pm 6.21^{\mathrm{a}}$ & $34.17 \pm 2.75$ & $33.16 \pm 7.89$ \\
\hline$C$ & $39.56 \pm 3.88$ & $41.44 \pm 12.29$ & $45.07 \pm 3.04$ & $41.19 \pm 7.13$ \\
\hline$h$ & $32.44 \pm 3.63$ & $45.81 \pm 10.64$ & $49.83 \pm 6.37$ & $53.18 \pm 4.98$ \\
\hline$\Delta \mathrm{E}$ & & & 7.74 & 5.53 \\
\hline
\end{tabular}

* Results show means \pm standard deviation. Different superscript letters indicate a significant difference at $\mathrm{p}<0.05$ level between cultivars 
The moisture content of the two strawberry leathers were 12.61\% ("Murano") and 9.85\% ("Malga"). No significant differences were found between moisture content of fruit leathers from the two strawberry cultivars $(\mathrm{p}<0.05)$. Previously, Addai et al. (2016) reported $14.31 \%$ and $15.42 \%$ moisture content in leathers of two papaya cultivars while Huang and Hseih (2005) found relative low moisture contents in pear fruit leathers, ranging from $6.42 \%$ to $13.47 \%$. Lower levels of moisture content suppress bacterial development and extend shelf life of fruit leathers, but may have an adverse effect on texture quality (Irwandi et al., 1998).

In terms of instrumental color, the strawberry leather from "Malga" cultivar was lighter than the leather from "Murano" cultivar ( $L^{*}$ mean value of 31.43 and 30.20 , respectively); however, the differences were not significant. Lightness significantly decreased in fruit leathers as compared to the strawberry homogenates (Table 2). The $a^{*}$ values were significantly higher in "Murano" fresh homogenate as compared to "Malga", thus confirming the more reddish tint of the pulp of this variety.

For $a^{*}$ values a significant decrease was found in both strawberry cultivars after drying while $b^{*}$ values were higher in leathers than in fresh fruit homogenates. Chroma value, which is used to perceive the color intensity, was highest in "Murano" leather.

A comparison between fresh fruits and fruit leathers in terms of total phenolic content (TPC), total flavonoid content (TFC), total anthocyanins content (TAC) and DPPH antioxidant activity (AA) is presented in Table 3.

Table 3

Effect of processing on the total phenolics content, total flavonoids content, total anthocyanins content and DPPH antioxidant activity of two strawberry cultivars

\begin{tabular}{|l|c|c|c|c|}
\hline \multirow{2}{*}{ Cultivars } & \multicolumn{2}{|c|}{ Fresh } & \multicolumn{2}{c|}{ Leather } \\
\cline { 2 - 5 } & "Murano" & "Malga" & "Murano" & "Malga" \\
\hline $\begin{array}{l}\text { Total phenolics } \\
\text { content } \\
\text { (mg GAE/100 g) }\end{array}$ & $1308.59 \pm 42.94^{\mathrm{b}}$ & $1423.47 \pm 54.38^{\mathrm{a}}$ & $735.30 \pm 26.67^{\mathrm{b}}$ & $963.18 \pm 34.20^{\mathrm{a}}$ \\
\hline $\begin{array}{l}\text { Total flavonoids } \\
\text { content } \\
\text { (mg QE/100 g) }\end{array}$ & $538.58 \pm 23.22^{\mathrm{b}}$ & $694.17 \pm 25.04^{\mathrm{a}}$ & $217.29 \pm 9.77^{\mathrm{b}}$ & $259.99 \pm 11.56^{\mathrm{a}}$ \\
\hline $\begin{array}{l}\text { Total anthocyanins } \\
\text { content } \\
\text { (mg CG/100 g) }\end{array}$ & $134.68 \pm 4.84^{\mathrm{b}}$ & $181.43 \pm 6.39^{\mathrm{a}}$ & $43.93 \pm 1.65^{\mathrm{b}}$ & $65.18 \pm 2.33^{\mathrm{a}}$ \\
\hline $\begin{array}{l}\text { DPPH antioxidant } \\
\text { activity } \\
\text { (mmol rolox/100 g) }\end{array}$ & $35.21 \pm 1.68$ & $34.45 \pm 1.98$ & $20.95 \pm 0.78$ & $21.19 \pm 1.05$ \\
\hline
\end{tabular}

* Results show means \pm standard deviation. Different superscript letters indicate a significant difference at $\mathrm{p}<0.05$ level between cultivars

The TPC, TFC and TAC were higher both in the fresh fruit and in the leather of "Malga" cultivar than in "Murano". No significant differences were found between cultivars regarding the DPPH antioxidant activity. However, the DPPH antioxidant activity was higher in "Murano" (35.21 mmol Trolox/100 g) than in "Malga" homogenates $(34.45 \mathrm{mmol}$ Trolox/100 g).

As shown in Table 3, there were significant decreases $(p<0.05)$ in term of TPC, TFC and TAC of strawberry leather after drying. 
TPC of the leathers obtained from the two strawberry cultivars were lower as compared to TPC of the fresh fruits. TPC found in the strawberry leathers (735.3 mg GAE/100 g DW and $963.18 \mathrm{mg} \mathrm{GAE} / 100 \mathrm{~g}$ for "Murano" and "Malga", respectively) were lower than that found in mulberry leathers dried at $60^{\circ} \mathrm{C}(1179 \mathrm{mg} \mathrm{GAE} / 100 \mathrm{~g} \mathrm{DW})$ by Phuong et al. (2016) but higher than TPC reported by Minakschhi (2011) in blueberry leathers (446 mg GAE/100 g DW) or by Senem et al. (2013) in apricot leather (60.34 mg GAE/100 g DW).

The anthocyanin contents of strawberry leather decreased by $67.38 \%$ ("Murano") and $64.07 \%$ ("Malga") of the initial value found in fruit homogenate while total phenolic contents were reduced by $43.81 \%$ ("Murano") and 32.33\% ("Malga"). In addition, reductions of $40.5 \%$ ("Murano") and 38.5\% ("Malga") in the DPPH antioxidant activity of strawberry leathers were observed after drying.

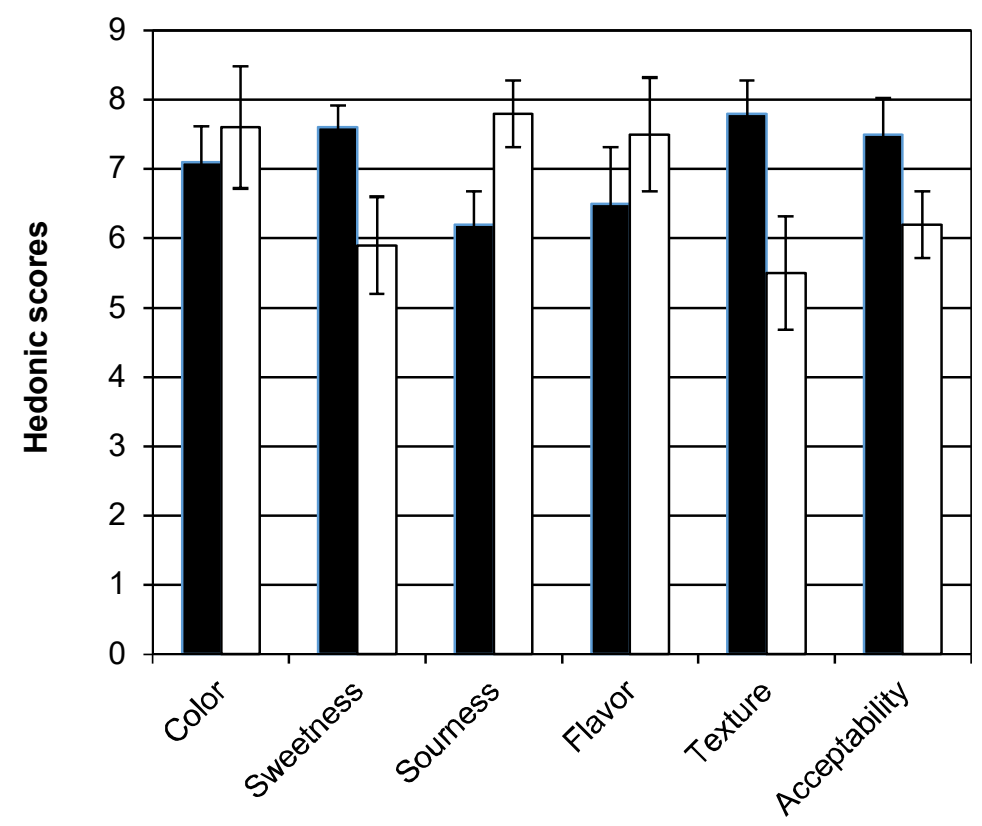

- Murano $\square$ Malga

Figure 1. Sensory evaluation of leathers made from two strawberry cultivars

The average scores for six properties of the fruit leathers are presented in Figure 1. Leathers from the two cultivars differed significantly $(p<0.05)$ in terms of sweetness, sourness, texture, and general acceptability.

Of the two cultivars, "Murano" leather achieved the lowest scores for color, however, the differences in color scores were not significant at $p<0.05$. There was a significant difference $(p<0.05)$ concerning sweetness scores, the leather made from "Murano" strawberries obtained an average sweetness score of 7.60 as compared with "Malga" (5.90). "Murano" leather was sweeter, in good agreement with its higher total soluble solids content, as compared with "Malga" leather. 
In terms of sourness and flavor, "Malga" stands out significantly with scores of 7.80 and 7.50 as compared to 6.20 and 6.50 for the "Murano" leather, respectively. Regarding the texture, "Murano" leather was much better appreciated (score 7.80) compared to "Malga" (score 5.50) because it was more elastic, softer and rehydrated faster during chewing.

\section{Discussion}

The addition of lemon juice to the fruit leather puree increased the titratable acidity of the leather from both strawberry cultivars. In addition, drying contributes to concentration in the fruit's natural acidity, leading to a substantial increase in the acidity of the fruit leather. Similar increases in titratable acidity after drying have been reported in previous studies (Phuong et al., 2016).

The higher levels of titratable acidity have a positive effect on leather shelf life as they inhibit bacterial growth and protect the color and flavor of the fruit product (Addai et al., 2016). Vega-Gálvez et al. (2009) reported an acidity of $2.2 \%$ (as citric acid) in dried blueberries while Vaidya et al. (2007) reported 3.8\% acidity in the fruit leather made from kiwifruit.

Fresh strawberry homogenates had a lighter color compared to the fruit leathers. The decrease of lightness after drying may be attributed to the loss of anthocyanins because of thermal degradation and to the formation of brown pigments as a result of the non-enzymatic oxidation of anthocyanins and subsequent condensation reactions (Singleton, 1987). In addition, citric acid is a strong acid that may affect the stability of anthocyanins, causing their degradation (Addai et al., 2016).

The decrease of $a^{*}$ values in both strawberry cultivars after drying may be due to anthocyanin oxidation as well as thermal degradation. Similar decreases of $a^{*}$ values were reported in papaya fruit leather after drying (Addai et al., 2016).

The reduction in total phenolic content after drying (by $43.81 \%$ and $32.33 \%$ in "Murano" and "Malga" leather, respectively) may be attributed to the heat sensitivity of phenolic compounds (Masibo and He, 2008), to the binding of phenolics to other compounds such as proteins or to the changes in their chemical structure (Di Scala et al., 2011). Suna (2019) reported a decrease of total phenolic content of $50.59 \%$ in medlar fruit leather after hot air drying at $60^{\circ} \mathrm{C}$. Similar decreases of TPC were reported in promeganate (Fatih et al., 2015), mulberry (Phuong et al., 2016), blueberry and rose hip leathers (Chen and Martynenko, 2018; Ruiz et al., 2014) and they were ascribed to the degradation and oxidation during heat treatment.

The loss of anthocyanins was found higher in both strawberry cultivars as compared with the loss of total phenolic content. This could be due to the higher sensitivity of anthocyanin compounds to thermal damage and process exposure time than colorless phenolic compounds (Karaaslan et al., 2014). Previous studies reported that total anthocyanin content reduced up to $80 \%$ in pomegranate fruit leather compared to initial mixture when increasing drying temperature from 50 to $70{ }^{\circ} \mathrm{C}$ (Fatih et al., 2015) while in mulberry leather the anthocyanin contents reduced from 22 to $72 \%$ of the initial value (Phuong et al., 2016).

Strawberries are known as an antioxidant source due to their high content of anthocyanin, phenolic and ascorbic acid. The decrease of the antioxidant activity after the processing of fruits in leathers may be attributed to the losses of antioxidant compounds as a result of their vulnerability to heat treatment (Brewer, 2011). Phuong et al. (2016) revealed that the free radical scavenging capacities positively correlated with TPC and TAC in mulberry leathers. 
Despite the higher $a^{*}$ values, the lowest color score was granted to "Murano" leather because of its paler appearance, in good agreement with its higher $L^{*}$ values. In addition, the color difference $(\Delta \mathrm{E})$ was significantly $(\mathrm{p}<0.05)$ higher in "Murano" processing, demonstrating the higher color degradation during drying in the fruit homogenates of this cultivar.

The taste of strawberry fruit leather was enhanced by adding honey and lemon juice. The sweetness of the fruit leather was influenced by the amount of sugar in the fresh pulp as was previously reported by Okilya et al. (2010). As found in previous studies, the panelists liked the product sweetness while the sourness of the fruit leathers was 'moderately liked' by the panelists (Addai et al., 2016). The strong aroma of the strawberries constituted a major asset to the strawberry leathers. The more persistent aroma of "Malga" strawberries resulted in a better grading of the flavor in "Malga" leather. However, in terms of general acceptability, there was a greater preference for the strawberry leather cultivar "Murano" (7.50) as compared with "Malga" (6.20) due to its reddish color, stronger sweetness, lower sourness and more pleasant texture.

\section{Conclusions}

1. The suitability of "Malga" and "Murano" strawberry cultivars as raw material for industrial processing in leathers was evaluated.

2. Apart from their attractive appearance, taste and flavor, strawberry leathers are a good source of natural antioxidants including anthocyanins and other phenolic compounds.

3. Significant decreases of phenolic content and antioxidant capacity was noted during the drying processing.

4. Further studies should focus on pre-treatment methods and ingredients for making strawberry leather in order to shorten drying time and maintain the antioxidant properties of the product.

\section{References}

Aaby K., Wrolstad R.E., Ekeberg D., Skrede G. (2007), Polyphenol composition and antioxidant activity in strawberry purees; impact of achene level and storage, Journal of Agricultural and Food Chemistry, 55(13), pp. 5156-5166.

Addai Z.R., Abdullah A., Mutalib S.A., Musa K.H. (2016), Evaluation of fruit leather made from two cultivars of papaya, Italian Journal of Food Science, 28, pp. 73-82.

Afrin S., Gasparrini M., Forbes-Hernandez T.Y., Reboredo-Rodriguez P., Mezzetti B., Varela-Lopez A., Giampieri F., Battino M. (2016), Promising health benefits of the strawberry: a focus on clinical studies, Journal of Agricultural and Food Chemistry, 64, pp. 4435-4449.

Al-Hinai K.Z., Guizani N., Singh V., Rahman M. S. and Al-Subhi L. (2013), Instrumental texture profile analysis of date-tamarind fruit leather with different types of hydrocolloids, Food Science and Technology Research, 19(4), pp. 531.

Ariza M.T., Reboredo-Rodríguez P., Mazzoni L., Forbes-Hernández T.Y., Giampieri F., Afrin S., Gasparrini M., Soria C., Martínez-Ferri E., Battino M., Mezzetti B. (2016), Strawberry achenes are an important source of bioactive compounds for human health, International Journal of Molecular Sciences, 17(7), pp. 1103. 
Bandaru H., Bakshi M. (2020), Fruit Leather: Preparation, packaging and its effect on sensorial and physico-chemical properties: A review, Journal of Pharmacognosy and Phytochemistry, 9(6), pp. 1699-1709.

Brewer M.S. (2011), Natural antioxidants: sources, compounds, mechanisms of action, and potential applications, Comprehensive Reviews of Food Science and Food Safety, 10, pp. 221-247.

Chen Y., Martynenko A. (2018), Combination of hydro-thermodynamic (HTD) processing and different drying methods for natural blueberry leather, LWT Food Science and Technology, 87, pp. 470-477.

Diamante L.M., Bai X., Busch J. (2014), Fruit leathers: Methods of preparation and effect of different conditions on qualities, International Journal of Food Science, 3, ID 139890, pp. $1-12$.

Di Scala K., Vega-Gálvez A., Uribe E., Oyanadel R., Miranda M., Vergara J., Quispe I., Lemus-Mondaca R. (2011), Changes of quality characteristics of pepino fruit (Solanum muricatum Ait) during convective drying, International Journal of Food Science and Technology, 46(4), pp. 746-753.

Fatih M.Y., Sultan Y., Hasan V., Mehmet K. (2015), The effects of drying conditions on moisture transfer and quality of pomegranate fruit leather (pestil), Journal of the Saudi Society of Agricultural Sciences, 16(1), pp. 33-40.

Forbes-Hernandez T.Y., Gasparrini M., Afrin S., Bompadre S., Mezzetti B., Quiles J.L., Giampieri F., Battino M. (2016), The healthy effects of strawberry polyphenols: Which strategy behind antioxidant capacity? Critical Review in Food Science and Nutrition, 56, pp. S46-59.

Giusti M.M., Wrolstad R.E. (2001), Unit F1.2: Anthocyanins. Characterization and measurement of anthocyanins with UV visible spectroscopy. In: Wrolstad R.E. (ed) Current protocols in food analytical chemistry, New York: John Wiley \& Sons, pp. 113.

Guo M., Jin T.Z., Gurtler J.B., Fan X., Yadav M.P. (2018), Inactivation of Escherichia coli O157:H7 and Salmonella and native microbiota on fresh strawberries by antimicrobial washing and coating, Journal of Food Protection, 81, pp. 1227-1235.

Hatano T., Kagawa H., Yasuhara T., Okuda T. (1988), Two new flavonoids and other constituents in licorice root: their relative astringency and radical scavenging effects, Chemical and Pharmaceutical Bulletin, 36, pp. 2090-2097.

Huang X., Hsieh F.H. (2005), Physical properties, sensory attributes and consumer preference of pear fruit leather, Journal of Food Engineering, 100(2), pp. 254-260.

Irwandi J., Man Y., Yusof S., Jinap S. and Sugisawa H. (1998), Effects of type of packaging materials on physicochemical, microbiological and sensory characteristics of durian fruit leather during storage, Journal of the Science of Food and Agriculture, 76(3), pp. 427-434.

Karaaslan M., Yilmaz F.M., Cesur O., Vardin H., Ikinci A., Dalgic A.C. (2014), Drying kinetics and thermal degradation of phenolic compounds and anthocyanins in pomegranate arils dried under vacuum conditions, International Journal of Food Science and Technology, 49(2), pp. 595-605.

Kowalska J., Kowalska H., Marzec A., Brzezin T., Samborska K., Lenart A. (2018), Dried strawberries as a high nutritional value fruit snack, Food Science and Biotechnology, 27, pp. 799-807.

Kumar R., Patil R., Mondal G. (2010), Development and evaluation of blended papaya leather, Acta Horticulturae, 851, pp. 565-570. 
Masibo M., He Q. (2008), Major mango polyphenols and their potential significance to human health, Comprehensive Reviews in Food Science and Food Safety, 7, pp. 309319.

Minakschhi K. (2011), Evaluation of fruit leathers made from New Zealand grown blueberries. A thesis submitted in partial fulfillment of the requirements for the Degree of Master of Science at Lincoln University.

Mohammadzadeh S., Sharriatpanahi M., Hamedi M., Amanzadeh Y., Sadat Ebrahimi S.E., Ostad S.N. (2007), Antioxidant power of Iranian propolis extract, Food Chemistry, 103, pp. 729-733.

Momchilova M., Zsivanovits G., Milkova-tomova I., Buhalova D., Dojkova P. (2016), Sensory and texture characterisation of plum (Prunus domestica) fruit leather, Bulgarian Chemical Communications, 48, pp. 428-434.

Nour V., Plesoianu A.M., Ionica M.E. (2021), Effect of dip wash treatments with organic acids and acidic electrolyzed water combined with ultraviolet irradiation on quality of strawberry fruit during storage, Bragantia, 80, e1921.

Okilya S., Mukisa I., Kaaya A. (2010), Effect of solar drying on the quality and acceptability of jackfruit leather, Electronic Journal of Environmental, Agricultural and Food Chemistry, 9(1), pp. 101-111.

Omolola A.O., Jideani A.I.O., Kapila P.F. (2017), Quality properties of fruits as affected by drying operation, Critical Reviews in Food Science and Nutrition, 57(1), pp. 95-108.

Parvez S., Wani, I.A. (2018). Postharvest biology and technology of strawberry, In S. Mir, M. Shah and M. Mir (Eds.), Postharvest Biology and Technology of Temperate Fruits, Cham: Springer, p. 331-348.

Phuong H.M.K., Hoa N.D.H., Ha N.V.H. (2016), Effects of added pectin amounts and drying temperatures on antioxidants properties of mulberry fruit leather, Journal of Biotechnology, 14(1A), pp. 487-495.

Phimpharian C., Jangchud A., Jangchud K., Therdthai N., Prinyawiwatkul W., No H.K. (2011), Physicochemical characteristics and sensory optimisation of pineapple leather snack as affected by glucose syrup and pectin concentrations, International Journal of Food Science and Technology, 46(5), pp. 972-981.

Ruiz N.A.Q., Demarchi S.M., Giner S.A. (2014), Effect of hot air, vacuum and infrared drying methods on quality of rose hip (Rosa rubiginosa) leathers, International Journal of Food Science and Technology, 49, pp. 1799-1804.

Senem S., Canan E., Bige İ.Ö.S.G., Ömer U. (2014), Impact of drying methods on physicochemical and sensory properties of apricot pestil, Indian Journal of Traditional Knowledge, 13(1), pp. 47-55.

Setiaboma W., Fitriani V., Mareta D.T. (2019), Characterization of fruit leather with carrageenan addition with various bananas, IOP Conf. Series: Earth and Environmental Science, 258, 012004.

da Silva Simão, R., de Moraes, J.O., Carciofi, B A.M., Laurindo, J.B. (2020), Recent advances in the production of fruit leathers, Food Engineering Reviews, 12(1), pp. 6882 .

Singleton V.L., Rossi J.A. (1965), Colorimetry of total phenolics with phosphomolybdic phosphotungstic acid reagent, American Journal of Enology and Viticulture, 16, pp. 144-158.

Singleton V.L. (1987), Oxygen with phenols and related reactions in musts, wines, and model systems: observations and practical implications, American Journal of Enology and Viticulture, 38(1), pp. 69-77. 
Suna S. (2019), Effects of hot air, microwave and vacuum drying on drying characteristics and in vitro bioaccessibility of medlar fruit leather (pestil), Food Science and Biotechnology, 28, pp. 1465-1474.

Van de Velde F., Tarola A., Güemes D., Pirovani M. (2013), Bioactive compounds and antioxidant capacity of camarosa and selva strawberries (Fragaria $x$ ananassa Duch.), Foods, 2, pp. 120-131.

Vaidya D., Vaidya M. and Sharma P. (2007), Development of value-added products from kiwifruit in India, Acta Horticulturae, 753(2), pp. 809.

Vega-Gálvez A., López J., Miranda M., Di Scala K., Yagnam F., Uribe E. (2009), Mathematical modelling of moisture sorption isotherms and determination of isosteric heat of blueberry variety $\mathrm{O}^{\prime}$ Neil, International Journal of Food Science \& Technology, 44(10), pp. 2033-2041. 